\title{
Prevalence of age-related hearing loss in Europe: a review
}

\author{
Thomas Niklaus Roth · Dirk Hanebuth · Rudolf Probst
}

Received: 6 December 2010 / Accepted: 29 March 2011 / Published online: 17 April 2011

(C) The Author(s) 2011. This article is published with open access at Springerlink.com

\begin{abstract}
Populations are becoming progressively older thus presenting symptoms of diminished organ function due to degenerative processes. These may be physiological or caused by additional factors damaging the organ. Presbyacusis refers to the physiological age-related changes of the peripheral and central auditory system leading to hearing impairment and difficulty understanding spoken language. In contrast to epidemiological data of other continents, the prevalence of age-related hearing loss (ARHL) in Europe is not well defined, due in part to the use of different classification systems. We performed a systematic literature review with the aim of gaining a picture of the prevalence of ARHL in Europe. The review included only population and epidemiological studies in English since 1970 with samples in European countries with subjects aged 60 years and above. Nineteen studies met our selection criteria and
\end{abstract}

Parts of this review were presented at the International Conference on Adult Hearing Screening in Cernobbio, Italy (June 10-12, 2010).

T. N. Roth $(\varangle) \cdot$ R. Probst

Department of Otorhinolaryngology, Head and Neck Surgery,

University Hospital of Zurich, Frauenklinikstr. 24,

8091 Zurich, Switzerland

e-mail: thomas.roth@usz.ch

D. Hanebuth

Department Epidemiology and Public Health,

Unit Gender and Health, Swiss Tropical

and Public Health Institute, Socinstrasse 57,

4002 Basel, Switzerland

\section{Hanebuth}

University of Basel, Petersplatz 1,

4003 Basel, Switzerland

D. Hanebuth

Department of Computer Science, ETH Zurich,

Universitätstrasse 6, 8092 Zurich, Switzerland additional five studies reported self-reported hearing impairment. When these data were crudely averaged and interpolated, roughly $30 \%$ of men and $20 \%$ of women in Europe were found to have a hearing loss of $30 \mathrm{~dB} \mathrm{HL}$ or more by age 70 years, and $55 \%$ of men and $45 \%$ of women by age 80 years. Apparent problems in comparing the available data were the heterogeneity of measures and cut-offs for grades of hearing impairment. Our systematic review of epidemiological data revealed more information gaps than information that would allow gaining a meaningful picture of prevalence of ARHL. The need for standardized procedures when collecting and reporting epidemiological data on hearing loss has become evident. Development of hearing loss over time in conjunction with the increase in life expectancy is a major factor determining strategies of detection and correction of ARHL. Thus, we recommend using the WHO classification of hearing loss strictly and including standard audiometric measures in populationbased health surveys.

Keywords Presbyacusis - Age-related hearing loss . Auditory system · Cochlear function · Epidemiology · Europe $\cdot$ AHEAD

\section{Introduction}

The age distribution of the populations of developed countries has changed dramatically during the twentieth century. The populations of Europe have become progressively older, particularly in the second half of the twentieth century. A recent projection suggested that the majority of babies being born in this century will become 100 years old or greater if the gain in longevity continues [1]. A steady linear growth of life expectancy to an undetermined biological 
limit was hypothesized in this study. However, other studies have considerably different aspects and factors limiting duration of life [2] and have even forecasted a declining life expectancy due to factors such as the consequences of the increased prevalence of obesity [3]. Moreover, the prevalence of diseases such as cancer or dementia, all with negative consequences, is clearly increasing because of longevity in our populations.

Fortunately, there is also good evidence that functional limitations and participation restrictions have diminished in the aged population along with the prolongation of life expectancy. Mobility and activities of daily living have improved. Age-related visual functional impairment has also decreased in the last decades, with cataract surgery contributing substantially to this improvement.

But what about hearing? Hearing loss (HL) is the most widespread sensory impairment in aging people. Hearing acuity declines with age-physiologically beginning by the third decade, predominately in the high frequencies [4]. It begins to affect the frequencies of the speech spectrum within the fifth decade. Age-related hearing loss (ARHL) is primarily a hearing loss related to functional loss of sensory [5, 6] and neural elements [7], comparable to macular degeneration in the visual system rather than what is referred to as presbyopia, which is related to conductive disturbances of the optical system. Presbyopia can be corrected relatively easily by cataract surgery, whereas presbyacusis exhibits multifaceted aspects also involving changes in neural structures responsible for central auditory processing. The cognitive and psychosocial consequences of HL are well described and well known [8], but populationbased epidemiological knowledge or trends on the amount of HL and its health-related consequences have not been well described.

Several aspects are of importance in this epidemiological context: differences in the definition of HL, different measurements of HL, and difficulties in measuring the activity limitations and participation restrictions induced by HL. Trends in improvement of age-related HL either connected to longevity or by intervention have also not been identified clearly.

The aim of this review was to evaluate epidemiological data with respect to prevalence of ARHL in Europe and, if possible, to identify trends of prevalence over the last 50 years. Moreover, based on our findings and including additional aspects, we will discuss procedures and strategies that may be included in future studies to improve epidemiologic knowledge of ARHL. Such knowledge may help to screen for ARHL, to induce earlier and more efficient interventions, and to reduce the burdens of ARHL.

\section{Methods}

Search methods

A systematic literature review was carried out with the specific aim of gaining a picture of the epidemiology of ARHL in Europe.

Table 1 lists the sources and the search strategy. We searched the proposed core data bases for a meta search in the category 'Medicine and Health'. These data bases partially overlap. Our search in the Library Catalogue of the University of Basel accessed the complete data base of the University of Basel (approximately 3 million titles) and those of 190 additional libraries of the Universities of Basel and Bern. The search was conducted in March and April 2010. Key words were entered in expressions with 'OR' when possible. The thesaurus function of PubMed (MeSH) was used to capture relevant alternative expressions for age-related hearing loss.

\section{Selection criteria}

The results were further searched manually. The references of relevant publications were systematically searched for additional relevant studies. We considered only population and epidemiological studies in English since 1970 with samples in European countries with subjects aged 60 years and above. For example, the study from Megighian et al. [9] was excluded because of a non-representative proportion of $92 \%$ males. A recent report from Davis et al. [10] had to be excluded from Table 3 because of the span of the age group, which was 55-75 years.

Table 2 shows the two main standardized categorizations [11-13]. A recent report of the WHO proposed that disabling hearing impairment in adults should be defined as a permanent unaided hearing threshold level for the better ear of $41 \mathrm{~dB}$ HL or greater $\left(\mathrm{PTA}_{0.5,1,2,4 \mathrm{kHz}} \geq 41 \mathrm{~dB} \mathrm{HL}\right.$ ) [14]. For reasons of homogeneity, we focused on prevalence data for the better ear (BEAR) and thresholds between 25 and $45 \mathrm{~dB}$ HL. Both audiometrically measured hearing loss (Table 3) and self-reported hearing loss (Table 4) were included. Some studies applied both methods of defining hearing loss.

\section{Results}

Numerical results from the search are summarized in Table 1. The search terms produced 1,150 results in Google scholar. These results were searched manually and com- 
Table 1 Search strategy

\begin{tabular}{|c|c|c|c|c|}
\hline Database $^{\mathrm{a}}$ & Search term & Number of results & Decision & Manual search of results \\
\hline \multirow[t]{3}{*}{$\begin{array}{l}\text { "Google Scholar" via VPN" of } \\
\text { University of Basel }\end{array}$} & $\begin{array}{l}\text { Prevalence AND } \\
\text { ("hearing loss") }\end{array}$ & $\begin{array}{l}\text { In document: } 31,900 \text {; } \\
\text { in title: } 217\end{array}$ & $\begin{array}{l}\text { Restricted search in } \\
\text { results for "in title" }\end{array}$ & 4 relevant \\
\hline & $\begin{array}{l}\text { Epidemiology AND } \\
\text { ("hearing loss") }\end{array}$ & $\begin{array}{l}\text { In document: } 21,400 \\
\text { in title: } 59\end{array}$ & $\begin{array}{l}\text { Restricted search in } \\
\text { results for "in title" }\end{array}$ & 0 additional results \\
\hline & $\begin{array}{l}\text { (prevalence OR epidemiology } \\
\text { OR epidemiological) AND } \\
\text { ("age-related hearing } \\
\text { loss" OR "presbyacusis") }\end{array}$ & $\begin{array}{l}\text { In document: } 1,150 \text {; } \\
\text { in title: } 5\end{array}$ & $\begin{array}{l}\text { Hand search in } \\
\text { all results }\end{array}$ & 38 additional results \\
\hline PubMed & See above & In document: 59 & $\begin{array}{l}\text { Manual search in } \\
\text { all results }\end{array}$ & 0 additional results \\
\hline $\begin{array}{l}\text { Recherche-Portal provided by } \\
\text { Hauptbibliothek } \\
\text { Universität Zürich }^{\mathrm{d}}\end{array}$ & See above & In document: 690 & $\begin{array}{l}\text { Manual search in } \\
\text { all results }\end{array}$ & 10 additional results \\
\hline $\begin{array}{l}\text { Eurostat; domain Health } \\
\quad{\text { (public health/safety at work })^{\mathrm{e}}}^{\mathrm{e}}\end{array}$ & $\begin{array}{l}\text { All above-mentioned } \\
\text { search term components }\end{array}$ & No results & & \\
\hline \multicolumn{5}{|c|}{${ }^{a}$ Search in databases followed a chronological order } \\
\hline \multicolumn{5}{|c|}{ b Virtual Private Network, allowed direct access to hosting organizations such as libraries and subscribed journals } \\
\hline \multicolumn{5}{|c|}{$\begin{array}{l}\text { Combinations of search terms yielded more results, ARHL (age-related hearing loss) and presbyacusis were chosen as the most appropriate target } \\
\text { expression }\end{array}$} \\
\hline \multicolumn{5}{|c|}{$\begin{array}{l}\text { d Meta Search in "Medicine and Health"/“Core Databases": CINAHL (EBSCO), Cochrane Library (Wiley), EMBASE.com, MEDLINE (Ovid- } \\
\text { SP), MEDLINE incl. Premedline, Premedline (OvidSP), PsycINFO (OvidSP), PubMed/Medline, Springer Protocols, Web of Science (ISI) XML } \\
\text { Gateway }\end{array}$} \\
\hline
\end{tabular}

Table 2 Standardized hearing loss categories

\begin{tabular}{lll}
\hline Categorization & (1) 'EU' classification & (2) 'WHO' classification \\
\hline Normal & $\mathrm{dB} \mathrm{HL}<21$ & $\mathrm{~dB} \mathrm{HL}<26$ \\
Mild & $21 \leq \mathrm{dB} \mathrm{HL}<39$ & $26 \leq \mathrm{dB} \mathrm{HL}<40$ \\
Moderate & $40 \leq \mathrm{dB} \mathrm{HL}<69$ & $41 \leq \mathrm{dB} \mathrm{HL}<60^{\mathrm{a}}$ \\
Severe & $70 \leq \mathrm{dB} \mathrm{HL}<94$ & $61 \leq \mathrm{dB} \mathrm{HL}<80$ \\
Profound & $94<\mathrm{dB} \mathrm{HL}$ & $80<\mathrm{dB} \mathrm{HL}$ \\
\hline
\end{tabular}

a According to the WHO, hearing impairments for the better ear of $41 \mathrm{~dB}$ HL or above have been defined as disabling

pared to the hits in the library catalogues. In a second step, the references of the selected papers were searched for further relevant publications with no further results.

There is a paucity of European epidemiological studies on age-related hearing loss in people aged 60 years and above $[15,16]$. Apparent problems in comparing the available data are the heterogeneity of measures and cut-offs for grades of hearing impairment $[15,17]$.

Table 3 lists the 19 studies in alphabetic order that met our selection criteria.

We found two Italian studies in two different samples $[18,19]$, six Swedish studies in three different samples [20-25], two Norwegian studies in one sample [26, 27], four Finish studies in three samples [12, 13, 28, 29], two British studies in two samples [30, 31], one study in
Sweden, Denmark and Finland with one of the aforementioned Finish samples [32], and a Dutch study [33].

Table 4 shows the results of another set of studies, again in alphabetical order. These studies describe self-reported hearing impairment. We found three British studies with three different samples [10, 30, 34], one study in Finland [28], one study in Denmark and Finland with the aforementioned Finish sample [32], one study in Sweden [35], and one study in Italy [36].

The study from Martini et al. is the only study that used published hearing categories [37]. All other studies used either a single post hoc dichotomized item to capture hearing impairments [28], a single post hoc tripartite item, one binary item [34], two binary items [10], or a single 5-point ordinal scale [30].

\section{Discussion}

Our systematic review of epidemiological data on prevalence of ARHL in Europe revealed more information gaps than information that would allow gaining a meaningful picture. Neither geographic distributions nor developments over time could be extracted to a reasonable degree. Most studies reported prevalence rates over age and frequency intervals; others reported data for single ages and frequencies. Because of this heterogeneity of the data, we were 
Table 3 Measured prevalence of age-related hearing loss $\geq 30 \mathrm{~dB}$ HL in elderly 60+ years: study overview

\begin{tabular}{|c|c|c|}
\hline Reference & Study & $\begin{array}{l}\text { Prevalence with nearest } \\
\text { cut-offs for HL and age }{ }^{\mathrm{a}}\end{array}$ \\
\hline Bedin et al. [18] & $\begin{array}{l}\text { Italy; multidisciplinary project in several } \\
\text { genetically isolated villages }\end{array}$ & Inapplicable data \\
\hline Bergmann and Rosenhall [20] & See Jonsson and Rosenhall [22], Jonsson et al. [23] & $>19 \%(70$ years at $30-39 \mathrm{~dB})$ \\
\hline Borchgrevink et al. [26] & $\begin{array}{l}\text { Norway; Supplement to the Nord-Trøndelag } \\
\text { Health Survey (Helseundersøkelsen i } \\
\text { Nord-Trøndelag, HUNT II); 1996-1998 }\end{array}$ & $>14.2 \%(60-64$ years at $35 \mathrm{~dB})$ \\
\hline Davis [30] & $\begin{array}{l}\text { UK; national epidemiological study; } \\
\text { MRC Institute of Hearing Research; 1980-1986 }\end{array}$ & $>7.4 \%(61-70$ years at $45 \mathrm{~dB})$ \\
\hline Davis [46] & See Davis (1989) [30] & $>24.5 \%(61-70$ years at $30 \mathrm{~dB})$ \\
\hline Engdahl et al. [27] & $\begin{array}{l}\text { Norway; Regular part of the Nord-Trøndelag } \\
\text { Health Survey (Helseunders } ø \text { kelsen i Nord-Trøndelag, } \\
\text { HUNT II); 1995-1997 }\end{array}$ & Inapplicable data ${ }^{\mathrm{b}}$ \\
\hline Hietanen et al. [32] & $\begin{array}{l}\text { Denmark, Sweden, Finland; NORA } \\
\quad \text { (Nordic Research on Aging); 1989-1991 }\end{array}$ & $>16.5 \%(75$ years at $40-69 \mathrm{~dB})$ \\
\hline Hietanen et al. [28] & Finland; 1990-2000 & $>28.3 \%(80$ years at $40-69 \mathrm{~dB})$ \\
\hline Johansson and Arlinger [21] & Sweden; 1998 & $>8.8 \%(60-70$ years at $35 \mathrm{~dB})$ \\
\hline $\begin{array}{l}\text { Jonsson and Rosenhall [22], } \\
\text { Jonsson et al. [23] }\end{array}$ & $\begin{array}{l}\text { Sweden; gerontological and geriatric population } \\
\text { study (H70); subjects born in period } \\
\text { 1st July 1901-30 June 1902; 1971-1992 }\end{array}$ & Inapplicable data ${ }^{c}$ \\
\hline Moller [24] & $\begin{array}{l}\text { Sweden;gerontological and geriatric population } \\
\text { study (H70-H75); 1971-1992; also see } \\
\text { Jonsson and Rosenhall [22] }\end{array}$ & $9 \%(70$ years at $35 \mathrm{~dB})$ \\
\hline Quaranta et al. [19] & Italy & $6.7 \%(61-70$ years at $45 \mathrm{~dB})$ \\
\hline Rahko et al. [29] & Finland; national "Project 65" study; 1975-1978 & $10.3 \%(65$ years at $30 \mathrm{~dB})$ \\
\hline Rosenhall et al. [25] & $\begin{array}{l}\text { Sweden; } N=237 \text { "Q/H70"; } 1992-1993 ; N=168 \text { "NORA"; } \\
\text { 1991-1992; } N=154 \text { "Gothenburg"; 1991-1990 }\end{array}$ & $24 \%(70$ years at $30-39 \mathrm{~dB})$ \\
\hline Smits and Houtgast [33] & $\begin{array}{l}\text { The Netherlands; "National Hearing" test (automatic } \\
\text { speech-in-noise screening test by telephone); } 2005\end{array}$ & Inapplicable data ${ }^{\mathrm{d}}$ \\
\hline Uimonen et al. [12] & Finland; hearing loss classification study & Inapplicable data ${ }^{\mathrm{e}}$ \\
\hline Uimonen et al. [13] & See Uimonen et al. [12] & Inapplicable data ${ }^{\mathrm{f}}$ \\
\hline Wilson et al. [31] & UK; 1989-1990 & $54.3 \%(\geq 65$ years at $35 \mathrm{~dB})$ \\
\hline
\end{tabular}

${ }^{a}$ Minimum prevalence in men and women for minimum better ear hearing loss of $30 \mathrm{~dB}$ and lower age interval border of 60 years

${ }^{\mathrm{b}}$ Graphical data report with threshold curves for separate pure tone frequencies

${ }^{c}$ Data report quartiles for cohorts and pure tone frequencies

${ }^{\mathrm{d}}$ Data report speech reception thresholds in noise

${ }^{e}$ Hearing loss interval (26-40 dB) falls below target cut-off $(30 \mathrm{~dB})$

${ }^{f}$ Age interval (55-75 years) falls below target cut-off (60 years)

unable to establish an integrative quantitative overview of prevalence rates over age and hearing loss. Nevertheless, the studies do reflect the well-known patterns of a nonlinear increase of hearing loss with age affecting men more than women. If the data are crudely averaged and interpolated, roughly $30 \%$ of men and $20 \%$ of women in Europe have a hearing loss of $30 \mathrm{~dB} \mathrm{HL}$ or more at age 70 years, and $55 \%$ of men and $45 \%$ of women at age 80 years.

These data confirm the known fact that ARHL is a major health concern in the aging population of Europe, but because of important information gaps, it is difficult to devise any recommendations. They demonstrate the need for standardized collection of epidemiological data on hearing loss.

Difficulties in data evaluation: classification of HL

An evident and primary difficulty in comparing reported prevalence data are the different measures and cut-offs for hearing impairment $[15,17]$. For example, the sample of the study in Denmark, Sweden and Finland consisted of 75year-old subjects, and results were subdivided in categories such as 'with minor difficulties' or 'with considerable difficulties' of hearing [32]. Other studies did not consistently 
Table 4 Self-reported prevalence of age-related hearing loss in elderly 60+ years: study overview

\begin{tabular}{|c|c|c|}
\hline Reference & Study & $\begin{array}{l}\text { Prevalence: impairments } \\
\text { of any kind }^{\mathrm{a}}\end{array}$ \\
\hline Chou [34] & $\begin{array}{l}\text { UK; English Longitudinal Study } \\
\text { of Ageing (ELSA), } \\
\text { wave I (2002-2003) and II (2005) }\end{array}$ & $>18.9 \%(\geq 65$ years $)$ \\
\hline Davis et al. [10] & UK; National Study of Hearing (NSH) & $>40.3 \%(\geq 75$ years $)$ \\
\hline Davis [30] & See Table 3 & $>14.6 \%$ ( $>60$ years $)$ \\
\hline Hietanen et al. [32] & $\begin{array}{l}\text { Denmark, Sweden, Finland; } \\
\text { NORA (Nordic Research on Aging); 1989-1991 }\end{array}$ & $>27.7 \%$ (75 years) \\
\hline Hietanen et al. [28] & Finland; 1990-2000 & $>44.7 \%$ ( 80 years $)$ \\
\hline Martini et al. [36] & Italy; 1989 & $>8.1 \%(>60$ years $)$ \\
\hline Rosenhall et al. [35] & $\begin{array}{l}\text { Sweden; Part of the Swedish Survey of } \\
\text { Living Conditions (ULF); conducted by } \\
\text { Statistics Sweden (SCB); 1986-1993 }\end{array}$ & $>16 \%(>64$ years $)$ \\
\hline
\end{tabular}

${ }^{a}$ Minimum prevalence in men and women for subjective hearing loss in study-specific impairment criterion

report sample sizes [35], had small sample sizes [28], or summarized results over all age groups [36]. Many studies reported data with cut-offs of $25 \mathrm{~dB}$ and $35 \mathrm{~dB}$ HL. One study [18] proposed an adaptive threshold model that uses different thresholds as a function of frequency [38], but without applying these thresholds in the reported data.

Prevalence is relatively easy to establish in clearly defined states, such as whether a person is alive or dead, or if a pathohistological diagnosis of cancer exists. Hearing loss is a gradual condition, and the limit between normal and not normal must be defined along a continuous scale. Obviously, the lack of a common definition prevents the availability of comparable prevalence data of HL. Standards such as ISO-7029 [4] define the distribution of normal hearing as function of age, but they do not define the limit of not normal hearing loss. Moreover, ISO-7029 is based on a linear model for ages 18-70 years not including the older ages with their nonlinear increase of hearing loss.

For the sake of acceptable homogeneity and to obtain an overview, we focused on prevalence data for the better ear and a range of cut-offs for the definition of hearing loss between 25 and $45 \mathrm{~dB}$ HL in the audiometric frequency range of $0.5-4 \mathrm{kHz}$. Tables 3 and 4 reveal that such limits cannot be regarded as a standard. In fact, it may be difficult to define any standard when evaluating the literature considered in this review. Even international classification systems such as those of the EU or the WHO differ considerably (Table 2). Because any definition of HL has unavoidably arbitrary elements, the acceptance and use of a standard definition of HL should be easy. It may be that the greater number of multitude of systems in use and the lack of knowledge of systems such as the WHO classification that hinder their regular use. It seems to us that the use of the WHO classification in the collection of epidemiological data is a logical step that could help to improve such data collection in the future. Universal acceptance and propagation of the WHO classification system is recommended.

Difficulties in data evaluation: selection of populations

Similar arbitrary limits occur when defining the "age" for prevalence in ARHL. Again, Tables 3 and 4 reveal that a standard age limit may be even more difficult to extract than the definition of HL. Even gender as a known significant influence on ARHL was not always clear. Only a portion of the studies explicitly reported prevalence rates for men and women, age groups, and hearing impairment categories [19, 21, 26, 28, 32]. Some studies either did not separate age and gender $[12,13,18,25,29,30,33]$, did not calculate row and column prevalence for hearing impairments among other impairments [20], did not report subsample sizes for age groups [26], had overlapping age class limits [18], or had inconsistent hearing loss criteria between age groups [29]. Three studies did not report prevalence data even though it seemed possible judging from the description of the data [22-24, 27]. In the study of Smits et al. [33] we derived approximate prevalence rates from a figure.

While international systems of HL classification exist, we are not aware of recommendations about the age limit defining ARHL. Even though the definition of such a limit may be biologically difficult if not impossible, it is highly desirable or even necessary to do so for epidemiological data. Again, for the sake of homogeneity this review set a lower age limit of 60 years.

\section{Connections between aetiology and epidemiology}

Epidemiology and aetiology are intimately related in that population-based endogenous factors will be exposed to 
geographically varying exogenous factors. One of our initial goals was to search for evidence linking epidemiology and aetiology.

As demonstrated in the previous sections, we have only a crude and patchy picture of the overall prevalence of ARHL in Europe. We know even less about the interaction of the different aetiological factors leading to what is termed ARHL. A separate overview of the literature not reported here in detail revealed that the most relevant factors in the aetiology of ARHL seem to be heredity (that may contribute up to $50 \%$ ), noise, history of chronic middle ear inflammation, and cardiovascular factors including diabetes, smoking and hypertension; additional relevant factors are hormones (including gender), exposure to ototoxic medication or chemicals and co-morbidities. As an example, ARHL seems to be more prevalent in patients with rheumatologic disease [39, 40].

Given the vast gaps in epidemiological knowledge, it is not surprising that we were not able to establish meaningful connections between epidemiology and aetiological factors. Besides the complex biological background, it is also the lack of clinical methods able to differentiate and measure the contributions of the different pathophysiological mechanisms that limits our ability to gain meaningful data on epidemiology and aetiology. The differentiation between peripheral and central hearing disturbance is often difficult to assess [41, 42]. Patients with impairment of the central nervous system typically also exhibit deficits in other cognitive functions that may affect daily life additionally or more severely than hearing loss Thus, unresolved questions about the reciprocal influence between hearing loss and cognition or isolation and central nervous function arise.

Geographic distribution in prevalence

Most studies observing the demographic pattern of hearing loss were made in the northern and western part of Europe, and there were only two studies in southern Europe [18, 19]. The findings of these two latter studies did not differ clearly from those of the other studies. Some additional data were found from Poland, the Netherlands, and Germany, but they were either inapplicable or not population based.

No geographic-related pattern could be derived from these data. The relative absence of studies in the middle, southern and eastern parts of Europe may reflect more the differences in public health systems than attaching less importance to ARHL in these regions. Nevertheless, given the fact that vowels have a distinct perceptual advantage over consonants in determining speech intelligibility [43, 44], the different languages spoken in Europe may also influence epidemiological data of ARHL with respect to prevalence of self-reported hearing impairment.
Screening for ARHL?

Ideally, a comprehensive strategy to screen, assess, and improve ARHL would be based not only on crude prevalence data and projections of its longitudinal development, but also on the prevalence of aetiologically different subsets. It seems likely that ARHL with a primary aetiological background of vascular or metabolic factors will need different preventive measures than an ARHL primarily connected to factors such as noise or due to inflammatory middle ear disease. Given the biological variability of ARHL, it may be difficult to devise a universal approach for improving ARHL. Rehabilitation strategies may also have to consider the contribution of peripheral and central auditory aspects [42, 45]. Testing these components selectively is not well established and no experience with screening for them exists.

\section{Conclusion}

This review of the literature did not allow us to gain a clear picture of the prevalence of ARHL in Europe. Development of hearing loss over time and in conjunction with the increasing life expectancy is a major factor determining strategies of detection and correction of ARHL. The need for standardized procedures when collecting and reporting epidemiological data on HL has become evident. We recommend adhering strictly to the WHO classification of HL and regularly including audiometric measure in populationbased health surveys.

Acknowledgments This work was supported by European Community's Seventh Framework Programme Project “AHEAD III: Assessment of Hearing in the Elderly: Aging and Degeneration- Integration through Immediate Intervention" (2008-2011) (contract No. HEALTH-F2-2008-200835). For further information see the weblink at http://www.ahead.polimi.it. We thank Fran Harris as a native English speaker for her linguistic corrections and suggestions.

Open Access This article is distributed under the terms of the Creative Commons Attribution Noncommercial License which permits any noncommercial use, distribution, and reproduction in any medium, provided the original author(s) and source are credited.

\section{References}

1. Christensen K et al (2009) Ageing populations: the challenges ahead. Lancet 374(9696):1196-1208

2. Carnes B, Olshansky S, Grahn D (2003) Biological evidence for limits to the duration of life. Biogerontology 4(1):31-45

3. Olshansky $\mathrm{S}$ et al (2005) A potential decline in life expectancy in the United States in the 21st century. N Engl J Med 352(11):1138-1145

4. International Standards-ISO 7029-2000 (2000) Acousticsstatistical distribution of hearing thresholds as a function of age. ISO, Geneva 
5. Soucek S, Michaels L, Frohlich A (1986) Evidence for hair cell degeneration as the primary lesion in hearing loss of the elderly. J Otolaryngol 15(3):175-183

6. Nelson E, Hinojosa R (2006) Presbycusis: a human temporal bone study of individuals with downward sloping audiometric patterns of hearing loss and review of the literature. Laryngoscope 116(9 Pt 3 Suppl 112):1-12

7. Frisina R, Walton J (2006) Age-related structural and functional changes in the cochlear nucleus. Hear Res 216-217:216-223

8. Monzani D et al (2008) Psychological profile and social behaviour of working adults with mild or moderate hearing loss. Acta Otorhinolaryngol Ital 28(2):61-66

9. Megighian D et al (2000) Audiometric and epidemiological analysis of elderly in the Veneto region. Gerontology 46(4):199-204

10. Davis A et al (2007) Acceptability, benefit and costs of early screening for hearing disability: a study of potential screening tests and models. Health Technol Assess 11(42):1-294

11. Martini A et al (1997) Audiometric patterns of genetic non-syndromal sensorineural hearing loss. Audiology 36(4):228-236

12. Uimonen $S$ et al (1999) Do we know the real need for hearing rehabilitation at the population level? Hearing impairments in the 5- to 75-year-old cross-sectional Finnish population. Br J Audiol 33(1):53-59

13. Uimonen S et al (1997) Hearing in 55 to 75 year old people in northern Finland-a comparison of two classifications of hearing impairment. Acta Otolaryngol Suppl 529:69-70

14. World Health Organization and Regional Office for South-East Asia (2001) Deafness and hearing impairment survey-report of the consultative meeting of principal investigators SEARO, New Delhi, 7-9 May 2001, WHO, New Delhi

15. Cruickshanks KJ, Zhan W, Zhong W (2010) Epidemiology of agerelated hearing impairment. In: Gordon-Salant $S$ et al (eds) The aging auditory system. Springer, Berlin, pp 259-274

16. Davis A, Davis K, Smith P (2009) The prevalence of deafness and hearing impairment. In: Graham J, Martin M (eds) Ballantyne's Deafness. Wiley, pp 6-19

17. Jerger $\mathbf{J}$ et al (1995) Hearing impairment in older adults: new concepts. J Am Geriatr Soc 43(8):928-935

18. Bedin E et al (2009) Age-related hearing loss in four Italian genetic isolates: an epidemiological study. Int J Audiol 48(7):465-472

19. Quaranta A, Assennato G, Sallustio V (1996) Epidemiology of hearing problems among adults in Italy. Scand Audiol Suppl 42:9-13

20. Bergmann B, Rosenhall U (2001) Vision and hearing in old age. Scand Audiol 30(4):255-263

21. Johansson MS, Arlinger SD (2003) Prevalence of hearing impairment in a population in Sweden. Int J Audiol 42(1):18-28

22. Jonsson R, Rosenhall U (1998) Hearing in advanced age. A study of presbyacusis in 85-, 88- and 90-year-old people. Audiology 37(4):207-218

23. Jonsson R et al (1998) Auditory function in 70- and 75-year-olds of four age cohorts. A cross-sectional and time-lag study of presbyacusis. Scand Audiol 27(2):81-93

24. Moller MB (1981) Hearing in 70 and 75 year old people: results from a cross sectional and longitudinal population study. Am J Otolaryngol 2(1):22-29

25. Rosenhall U, Karlsson Espmark AK (2003) Hearing aid rehabilitation: what do older people want, and what does the audiogram tell? Int J Audiol 42(Suppl 2):253-257
26. Borchgrevink HM, Tambs K, Hoffman HJ (2005) The NordTrondelag Norway Audiometric Survey 1996-98: unscreened thresholds and prevalence of hearing impairment for adults $>20$ years. Noise Health 7(28):1-15

27. Engdahl B et al (2005) Screened and unscreened hearing threshold levels for the adult population: results from the Nord-Trondelag Hearing Loss Study. Int J Audiol 44(4):213-230

28. Hietanen A et al (2004) Changes in hearing in 80-year-old people: a 10-year follow-up study. Int J Audiol 43(3):126-135

29. Rahko $\mathrm{T}$ et al (1985) Prevalence of handicapping hearing loss in an aging population. Ann Otol Rhinol Laryngol 94(2 Pt 1):140 144

30. Davis AC (1989) The prevalence of hearing impairment and reported hearing disability among adults in Great Britain. Int $\mathbf{J}$ Epidemiol 18(4):911-917

31. Wilson PS, Fleming DM, Donaldson I (1993) Prevalence of hearing loss among people aged 65 years and over: screening and hearing aid provision. Br J Gen Pract 43(375):406-409

32. Hietanen A et al (2005) Hearing among 75-year-old people in three Nordic localities: a comparative study. Int J Audiol 44(9):500-508

33. Smits C, Houtgast T (2005) Results from the Dutch speech-in-noise screening test by telephone. Ear Hear 26(1):89-95

34. Chou KL (2008) Combined effect of vision and hearing impairment on depression in older adults: evidence from the English Longitudinal Study of Ageing. J Affect Disord 106(1-2):191-196

35. Rosenhall U, Jonsson R, Soderlind O (1999) Self-assessed hearing problems in Sweden: a demographic study. Audiology 38(6):328334

36. Martini A et al (2001) Hearing in the elderly: a population study. Audiology 40(6):285-293

37. Sanders DA (1975) Hearing aid orientation and counselling. In: Pollack MC (ed) Amplification for the hearing-impaired. Grune and Stratton, New York, pp 121-128

38. Sakamoto $\mathrm{M}$ et al (1998) Average thresholds in the 8 to $20 \mathrm{kHz}$ range as a function of age. Scand Audiol 27(3):189-192

39. Murdin L et al (2008) Hearing difficulties are common in patients with rheumatoid arthritis. Clin Rheumatol 27(5):637-640

40. George D, Pradhan S (2009) Idiopathic sensorineural hearing disorders in adults - a pragmatic approach. Nat Rev Rheumatol 5(9):505-512

41. Gates G, Popelka G (1992) Neural presbycusis: a diagnostic dilemma. Am J Otol 13(4):313-317

42. Otto W, McCandless G (1982) Aging and auditory site of lesion. Ear Hear 3(3): 110-117

43. Kewley-Port D, Burkle T, Lee J (2007) Contribution of consonant versus vowel information to sentence intelligibility for young normal-hearing and elderly hearing-impaired listeners. J Acoust Soc Am 122(4):2365-2375

44. Fogerty D, Kewley-Port D (2009) Perceptual contributions of the consonant-vowel boundary to sentence intelligibility. J Acoust Soc Am 126(2):847-857

45. Gates G, Mills J (2005) Presbycusis. Lancet 366(9491):11111120

46. Davis A (1995) Hearing in adults. Whurr, London 